\title{
Estudo Bibliométrico da Área Ensino e Pesquisa em Gestão de Custos: Triênio 2007-2009 do Congresso Brasileiro de Custos ${ }^{1}$
}

\section{Bibliometric Study Area of Teaching and Research in Management Costs: 2007-2009 Triennium of the Brazilian Congress Cost}

\author{
Valdério Freire de Moraes Júnior \\ Professor Assistente da Universidade Federal da Paraíba \\ Centro de Ciências Sociais Aplicadas - Campus I, Departamento de Finanças e Contabilidade. Cidade Universitária s/n, Castelo Branco \\ CEP: 58059-900 - Joao Pessoa, PB - Brasil, Telefone: (83) 32167459, e-mail: valderiojunior@hotmail.com
}

\section{Aneide Oliveira Araújo}

Professora do Departamento de Ciências Contábeis da UFRN e do Programa Multiinstitucional e Inter-regional de Pós-Graduação em Ciências Contábeis UnB/UFRN/UFPB. Endereço: Universidade Federal do Rio Grande do Norte -Centro de Ciências Sociais Aplicadas - Departamento de Ciências Contábeis, Av. Senador Salgado Filho, S/N, Campus Universitário, Lagoa Nova, Natal -RN -Brasil, CEP 59076-000, e-mail: aneide@ufrnet.br

Isabelle Carlos Campos Rezende

Professora Assistente do Departamento de Ciências Sociais Aplicadas da Universidade Federal da Paraíba, Campus IV, Litoral Norte. Rua Escritor José Vieira, s/n, Centro, 58280000 - Mamanguape, PB - Brasil. Telefone: (83) 3292-2778, e-mail: isabelle 1236@hotmail.com

\section{RESUMO}

\begin{abstract}
O presente estudo objetiva fazer um levantamento, no período de 2007 a 2009, da área "ensino e pesquisa na gestão de custos" integrante do Congresso Brasileiro de Custos (CBC). Por sua vez, a metodologia utilizada partiu de um estudo bibliométrico, através da pesquisa descritiva e de levantamento de dados. $O$ trabalho é considerado quantitativo, no que diz respeito ao mapeamento realizado e qualitativo pela verificação das informações que foram analisadas nos 49 artigos que compõe o triênio estudado. Os resultados encontrados revelam que 15 artigos foram aprovados no ano de 2007, já em 2008 foram selecionados 16 trabalhos e em 2009, esse número aumentou para 18. O número de IES que os autores vincularam seus trabalhos foi de 36. Já a metodologia utilizada nos artigos mapeou os seguintes elementos: abordagens, procedimentos e objetivos, com o seguinte resultado: a região com $40 \%$ de trabalhos aprovados é a Sudeste, sendo que no triênio analisado, a FURB (Universidade Regional de Blumenau) teve 8 artigos selecionados, entre as 36 Instituições de Ensino Superior que aprovaram textos na área temática estudada. Por fim, levantou-se 43 temáticas diferentes na área "ensino e pesquisa na gestão de custos" no triênio estudado.
\end{abstract}

Palavras-chaves: Congresso. Ensino e Pesquisa. Bibliometria.

\section{ABSTRACT}

The present study aims to conduct a survey for the period 2007-2009, the area "teaching and research on cost management" member of the Brazilian Congress of costs (CBC). In turn, the methodology used was a bibliometric study, through a descriptive research and a data collection. The work is considered quantitative with respect to the mapping realized and qualitative by check the information were analyzed in 49 articles that comprise the period studied. The results show that 15articles were approved in 2007, in 2008 were selected 16 works and in 2009 that number increased to 18. The number of IES that the authors linker their works was 36. Since the methodology used in articles mapped the following items: approaches, procedures and objectives, with the following result: the region with $40 \%$ of approved works is the Southeast and in the triennial analyzed the FURB (Regional University of Blumenau) had 08 articles selected among the 36 Higher Education Institutions that approved texts on the thematic area studied. Finally, rose 43 different thematic in the area "teaching and research in the management costs" in the period studied.

Keywords: Congress. Teaching and Research. Bibliometrics.

\footnotetext{
${ }^{1}$ Artigo recebido em 10.05.2012. Avaliado pelos pares em 10.04.2013. Reformulado em 23.05.2013. Aceito para publicação em 01.06.2013. Recomendado para publicação por José Ribamar Marques de Carvalho (Editor Científico). Publicado em 17.07.2013
} 


\section{INTRODUÇÃO}

Inquietos com a inadequação dos sistemas de contabilidade gerencial às necessidades das empresas, Johnson e Kaplan, em setembro de 1986, publicaram o livro Relevance Lost.

Naquela oportunidade discutia-se a perda de relevância da informação de custo, cujos princípios de mensuração remontavam-se ao inicio do século XIX, conforme Johnson e Kaplan (1993) e se prestavam, essencialmente, a atribuição de valor aos estoques, contribuindo para algumas decisões de natureza operacional, mas de pouca serventia ao processo de gestão estratégica, embora apoiasse o processo de orçamento de capital e avaliação do desempenho divisional.

Na época, Johnson e Kaplan (1993, p. 169) afirmavam: “os sistemas de contabilidade de custos típicos dos anos 80 não servem nem para a avaliação de custo dos produtos, nem para o controle de custos operacionais: suas informações não são proveitosas para a gerência de custos". Esta opinião fazia parte de um crescente movimento pelo resgate do papel original da informação de custos pelos usuários internos para propósitos estratégicos, contribuindo para o que, em seguida, veio a se denominar 'revolução dos custos' (grifo nosso).

Para que haja uma disseminação do que está sendo pesquisado, o meio mais utilizado são os congressos e periódicos pelos estudiosos, através do conhecimento que é gerado pelas produções científicas, promovendo o chamado desenvolvimento científico-social (OLIVEIRA, 2002).

O evento denominado Congresso, um espaço aberto para difusão do conhecimento, é utilizado pelos pesquisadores para divulgação do que está sendo estudado de mais recente em uma determinada área. Na área contábil não é diferente, podendo ser citado alguns eventos como: o Congresso Brasileiro de Contabilidade, o Encontro Nacional de Pós-Graduação em Administração (Enanpad), a Associação Nacional de Pós-Graduação em Ciências Contábeis (ANPCONT), o Congresso USP de Controladoria e Contabilidade e o Congresso Brasileiro de Custos, que ocorrem em diferentes épocas, entretanto, proporcionam a interação entre estudantes e profissionais das áreas afins com a Contabilidade.

O primeiro Congresso Brasileiro de Custos, ocorrido em São Leopoldo, cidade do Rio Grande do Sul acontece desde 1994 e é considerado um dos mais importantes eventos da área contábil no país, tendo conceito nível A1 pela Capes, sendo objeto de estudo para os pesquisadores de uma forma geral, devido a sua relevância, principalmente à área de custos empresarias no Brasil. Na época, o evento contou com a participação de mais de 300 participantes do Brasil e do MERCOSUL.

Os programas de pós-graduação, em geral, são relevantes colaboradores da pesquisa científica nos eventos. O surgimento desses programas ocorreu na década de 60 , do século passado, sendo que a regulamentação saiu através do Decreto no 
977/65, do antigo Conselho Federal de Educação. Na área de Ciências Contábeis, o primeiro programa foi o da Universidade de São Paulo.

O objetivo desse trabalho é fazer um levantamento, no período de 2007 a 2009, da área "ensino e pesquisa na gestão de custos" integrante do Congresso Brasileiro de Custos (CBC). Para tanto, surge o seguinte questionamento de pesquisa: Quais tipos de metodologia e temáticas foram utilizados pelos autores envolvidos nos trabalhos selecionados na área de ensino e pesquisa na gestão de custos, que faz parte do CBC, no triênio 2007-2009?

Sendo assim, a metodologia utilizada partiu de um estudo bibliométrico, através de uma pesquisa descritiva e de levantamento de dados. O trabalho é considerado quantitativo, no que diz respeito ao mapeamento realizado e qualitativo pela verificação das informações que foram analisadas nos 49 artigos que compõe o triênio estudado.

Além dessa introdução, que apresenta a proposta desse trabalho, esse artigo está dividido em mais quatro seções: na segunda parte, que é o referencial teórico sobre o tema abordado, na terceira seção sobre a metodologia utilizada, a quarta é a análise dos resultados e a quinta seção traz as considerações finais.

\section{FUNDAMENTAÇÃO TEÓRICA}

Essa seção versa sobre a revisão da literatura sobre o tema proposto, com base nos seguintes tópicos: breve retrospecto da pesquisa em contabilidade gerencial; bibliometria; estudos bibliométricos em Contabilidade e metodologia da pesquisa aplicada à Contabilidade.

\subsection{Breve retrospecto da pesquisa em contabilidade gerencial}

Calcular custo de produtos e controlar mão-de-obra e materiais diretos constituía-se, até a primeira metade do século XX, segundo Ryan, Scapens e Theobald (2004), no enfoque principal da contabilidade orientada para o processo decisório dentro das empresas, ou seja, da contabilidade de gestão. Desde então grandes e profundas modificações no contexto da pesquisa em contabilidade de custo foram registradas distanciando-se do foco na sua mensuração exata para o reconhecimento do custo relevante a uma determinada decisão.

Reconheceu-se, também, que a informação de custos, baseada nos pressupostos da economia neoclássica isolada não era suficiente para permitir julgamentos e decisões, recorrendo-se a contribuições tanto da teoria das organizações quanto das ciências comportamentais e, mais recentemente, da teoria de decisão estatística no sentido de minimizar a influencia da incerteza inerente ao ambiente dinâmico empresarial (RYAN; SCAPENS; THEOBALD, 2004). 
Tendo como cerne a teoria neoclássica, as pesquisas orientadas para a satisfação informacional dos gestores seguiram incorporando sofisticados recursos quantitativos, porém limitados metodologicamente, haja vista que estão pautados em princípios de racionalidade técnica, podendo predizer comportamentos individuais isolados, mas não do contexto socioeconômico em que se inserem as empresas. Procurando minimizar estes aspectos, correntes alternativas incorporaram contribuições das teorias comportamental e social que, de algum modo, se baseiam no modo como atuam os profissionais da área, direcionando os estudos para "o desenvolvimento e aplicação de novas técnicas da gestão de custos, mensuração de resultados financeiros, gestão estratégica, etc.", conforme Ryan, Scapens e Theobald (2004, p. 124).

\subsection{Bibliometria}

A Bibliometria é uma das áreas da Ciência da Informação, através da qual pode ser aplicada métodos estatísticos e matemáticos, para ser feita uma análise do curso de comunicação de todos os estudos que possam ser quantificados, por exemplo, em uma disciplina ministrada. Segundo Pritchard (1969), as principais características da bibliometria são:

1) Identificar as tendências e crescimento do conhecimento com base em uma matéria;

2) Estudar dispersão e obsolescências de certos assuntos científicos;

3) Medir impacto dos estudos publicados e as informações disseminadas no meio acadêmico;

4) Quantificar a cobertura das revistas cientificas;

5) Identificar autores e instituições mais produtivos.

Willians e Rodgers (1996) discutiram a base nos padrões de pesquisa, produtividade de autores e criação de novos conhecimentos no periódico norteamericano The Accounting Review no período de 1967 a 1993 e identificaram uma estratificação em publicações em outras áreas do conhecimento.

Hesford, Van Der Stede e Young (2007), por sua vez, levaram em consideração os aspectos metodológicos ao se fazer um estudo bibliométrico. Principalmente no que tange as abordagens feitas, procedimentos escolhidos e objetivos traçados no trabalho.

A bibliometria também serve para verificar de que forma os estudos estão sendo discutidos dentro da academia, já que ela faz o levantamento da área, através das temáticas abordadas nas pesquisas. Dessa forma, as revistas científicas sofrem uma cobertura do que está sendo explorado, identificando autores que mais 
produzem, como também as instituições que estão vinculadas os estudos (AHRENS; CHAPMAN, 2006).

Portanto, pode-se dizer que os estudos bibliométricos geralmente são utilizados para quantificar dados referentes a um determinado assunto que está sendo discutido em uma determinada área. A intenção é mostrar quais são as tendências da área estudada e, de que forma, está ocorrendo o interesse dos pesquisadores nela; como também, verificar quais assuntos se tornaram ultrapassados.

\subsection{Estudos bibliométricos na Contabilidade brasileira}

$\mathrm{Na}$ área de Contabilidade, estudos bibliométricos ainda são recentes, principalmente no Brasil. Porém, por se tratar de um assunto relevante, tem sido explorado em Congressos e revistas nacionais.

Na pesquisa feita por Araújo, Oliveira e Silva (2009), houve um delineamento da produção científica do Enanpad de 2004 a 2008, ou seja, um período de 5 anos, referente a área da Contabilidade Gerencial. No trabalho dos autores supracitados, é apresentado um quadro resumo de pesquisas anteriores que são comentadas também nesse estudo. $\mathrm{O}$ quadro 1 mostra os autores, objetivos e considerações ou conclusões dessas pesquisas:

\begin{tabular}{|c|c|c|}
\hline AUTOR(ES) & OBJETIVO(S) & CONSIDERAÇÕES/CONCLUSÃO \\
\hline Oliveira (2002) & $\begin{array}{l}\text { Fazer uma análise dos } \\
\text { periódicos da área contábil. }\end{array}$ & $\begin{array}{l}\text { Verificou uma mudança no paradigma } \\
\text { contábil, com o foco na área gerencial. } \\
\text { Relatou que há uma carência de } \\
\text { publicações voltadas à Contabilidade } \\
\text { internacional, mercado de capitais, } \\
\text { Contabilidade social e ambiental. }\end{array}$ \\
\hline $\begin{array}{l}\text { Mendonça Neto } \\
\text { et al (2004) }\end{array}$ & $\begin{array}{l}\text { Analisar a metodologia } \\
\text { adotada, a evolução, a } \\
\text { temática e a produtividade } \\
\text { dos autores que publicaram } \\
\text { nas revistas de Contabilidade } \\
\text { (Qualis A - Capes). }\end{array}$ & $\begin{array}{l}\text { São Paulo foi o Estado que mais publicou, } \\
\text { com } 51,11 \% \text { dos artigos. Já as IES com } \\
\text { maior número de publicações foram: USP, } \\
\text { FGV-SP, FGV-RJ e UFRGS. }\end{array}$ \\
\hline $\begin{array}{l}\text { Leite } \\
\text { (2006) }\end{array}$ & $\begin{array}{l}\text { Verificar a produtividade } \\
\text { científica dos autores em } \\
\text { anais de congressos e } \\
\text { periódicos contábeis no } \\
\text { Brasil. }\end{array}$ & $\begin{array}{l}\text { Os autores mais produtivos representam } \\
\text { mais de } 26 \% \text { dos artigos, há uma } \\
\text { concentração de autoria com vínculo a um } \\
\text { número pequeno de instituições e a } \\
\text { maioria dos pesquisadores é do sexo } \\
\text { masculino. }\end{array}$ \\
\hline $\begin{array}{l}\text { Cardoso et al } \\
(2007)\end{array}$ & $\begin{array}{l}\text { Levantar um perfil do } \\
\text { Enanpad (1998 - 2000), em } \\
\text { relação à área de custos e } \\
\text { Contabilidade Gerencial. }\end{array}$ & $\begin{array}{l}\text { O crescimento qualitativo das pesquisas na } \\
\text { área de custos não ocorreu, mesmo com } \\
\text { um aumento quantitativo de artigos nessa } \\
\text { área. }\end{array}$ \\
\hline Kroenke & Analisar as publicações sobre & Levando-se em consideração as palavras- \\
\hline
\end{tabular}




\begin{tabular}{|l|l|l|}
\hline Cunha (2008) & $\begin{array}{l}\text { harmonização contábil em } \\
\text { eventos nacionais Qualis A - } \\
\text { Capes), no período de 2004 a } \\
\text { 2007. }\end{array}$ & $\begin{array}{l}\text { chave, há uma concentração de artigos } \\
\text { selecionados no Enanpad. }\end{array}$ \\
\hline $\begin{array}{l}\text { Silva, } \\
\text { Albuquerque e e } \\
\text { Gomes (2008) }\end{array}$ & $\begin{array}{l}\text { Fazer uma discussão sobre a } \\
\text { controvérsia do paradigma } \\
\text { econômico na pesquisa } \\
\text { empírica em Gerencial, } \\
\text { proposta por Zimmerman, } \\
\text { criticada por alguns } \\
\text { estudiosos. }\end{array}$ & $\begin{array}{l}\text { Através de um consenso, observou-se que } \\
\text { o paradigma econômico de forma isolada } \\
\text { nantabilidade Gerencial, tendo vista a } \\
\text { complexidade que faz parte dessa área. }\end{array}$ \\
\hline $\begin{array}{l}\text { Faro e Silva } \\
\text { (2008) }\end{array}$ & $\begin{array}{l}\text { Observar o aparecimento de } \\
\text { áreas novas de pesquisas em } \\
\text { Gerencial, a partir de 1996. }\end{array}$ & $\begin{array}{l}\text { Ocorreu um aumento das pesquisas que } \\
\text { tratam de Sistemas de Informações } \\
\text { Gerenciais (SIG). Como também, } \\
\text { publicações de áreas novas. }\end{array}$ \\
\hline
\end{tabular}

Quadro 1: Estudos bibliométricos na contabilidade brasileira

Fonte: Adaptado de Araújo, Oliveira e Silva (2009).

Oliveira (2002) fez uma análise dos periódicos de Contabilidade e constatou uma tendência dos autores em optar por trabalhos na área gerencial, acarretando uma carência em outras áreas, como por exemplo, a de mercado de capitais.

Já Mendonça Neto et. al. (2004) foram mais além, analisando também os periódicos da área contábil, mas levando em consideração as metodologias adotadas, temáticas e a produtividade dos autores, para chegar a seguinte conclusão: as IES do Estado de São Paulo são as que mais têm publicações feitas.

Leite Filho (2006) foi mais abrangente, considerando, não somente os periódicos, mas também os Anais dos Congressos brasileiros. $\mathrm{O}$ autor percebeu que os autores mais produtivos estão vinculados a um número reduzido de IES e são do sexo masculino. Por sua vez, Cardoso et al. (2007) limitou-se ao Enanpad (1998-2000), no tocante à área de custos e gerencial, chegando a conclusão que o aumento do número de trabalhos, no período, fez diminuir a qualidade dos artigos.

Consoante Kroenke e Cunha (2008) fez uma análise com base em eventos nacionais sobre harmonização contábil, no período de 2004 a 2007, chegando a conclusão que há uma concentração dessa temática no Enanpad.

Silva, Albuquerque e Gomes (2008) levantaram uma discussão sobre a controvérsia do paradigma econômico na pesquisa empírica na área gerencial, com base em Zimmerman, que é criticada por alguns estudiosos, mas não chegaram a um denominador comum sobre a complexidade da área em questão. Por sua vez, Faro e Silva (2008), dentro dessa mesma área, procuraram investigar novas temáticas de pesquisa, concluindo que houve principalmente um aumento de pesquisas sobre SIG. 


\subsection{Metodologia aplicada à Contabilidade}

A Contabilidade, por ser um dos campos da área das ciências sociais, tem procedimentos metodológicos próprios, em relação aos trabalhos científicos, levando-se em consideração à delimitação do tema, problema, objetivos e justificativa. Segundo Raupp e Beuren (2004), os problemas acabam sendo identificados, baseando-se no delineamento da pesquisa e das respostas encontradas.

Nesse sentido, os autores citados anteriormente afirmam que o delineamento da pesquisa faz com que haja a escolha de um plano que consiga conduzir a investigação, ocorrendo certas limitações e novos problemas são identificados, com base nelas.

\begin{tabular}{|c|c|c|}
\hline Andrade (2002) & Vergara (1997) & Santos (1999) \\
\hline $\begin{array}{l}\text { Quanto à natureza } \\
\text { - trabalho científico } \\
\text { original } \\
\text { - resumo de assunto }\end{array}$ & \multirow{2}{*}{$\begin{array}{l}\text { Quanto aos fins } \\
\text { - exploratória } \\
\text { - descritiva } \\
\text { - explicativa } \\
\text { - metodológica } \\
\text { - aplicada } \\
\text { - intervencionalista }\end{array}$} & $\begin{array}{l}\text { Quanto aos objetivos } \\
\text { - exploratórias } \\
\text { - descritivas } \\
\text { - explicativas }\end{array}$ \\
\hline \multirow{2}{*}{$\begin{array}{l}\text { Quanto aos objetivos } \\
\text { - pesquisa exploratória } \\
\text { - pesquisa descritiva } \\
\text { - pesquisa explicativa }\end{array}$} & & $\begin{array}{l}\text { Quanto aos procedimentos de } \\
\text { coleta } \\
\text { - experimento }\end{array}$ \\
\hline & \multirow{4}{*}{$\begin{array}{l}\text { Quanto aos meios } \\
\text { - pesquisa de campo } \\
\text { - pesquisa de laboratório } \\
\text { - telematizada } \\
\text { - documental } \\
\text { - bibliográfica } \\
\text { - experimental } \\
\text { - ex-post-facto } \\
\text { - participante } \\
\text { - pesquisa-ação } \\
\text { - estudo de caso }\end{array}$} & $\begin{array}{l}\text { - levantamento } \\
\text { - estudo de caso }\end{array}$ \\
\hline $\begin{array}{l}\text { Quanto aos procedimentos } \\
\text { - pesquisa de campo } \\
\text { - pesquisa descritiva } \\
\text { - pesquisa explicativa }\end{array}$ & & $\begin{array}{l}\text { - pesquisa documental } \\
\text { - pesquisa-ação } \\
\text { - pesquisa participante } \\
\text { - pesquisa ex-pos-facto } \\
\text { - pesquisa quantitativa }\end{array}$ \\
\hline \multirow{2}{*}{$\begin{array}{l}\text { Quanto aos procedimentos } \\
\text { - pesquisa bibliográfica } \\
\text { - pesquisa de laboratório } \\
\text { - pesquisa de campo }\end{array}$} & & - pesquisa qualitativa \\
\hline & & $\begin{array}{l}\text { Quanto às fontes de } \\
\text { informação } \\
\text { - campo } \\
\text { - laboratório } \\
\text { - bibliográfica }\end{array}$ \\
\hline
\end{tabular}

Quadro 2: Tipologias de delineamentos de pesquisas com agrupamentos

Fonte: Raupp e Beuren (2004, p. 79)

Ao observar o quadro 2 nota-se as tipologias de delineamentos de pesquisas com agrupamentos, com base nas obras de autores de metodologia científica. Dessa maneira, as tipologias são divididas dentro da Contabilidade, de forma que sejam mais aplicadas a essa ciência, dividindo-se em três categorias, conforme Raupp e Beuren (2004): pesquisa quanto aos objetivos, contemplando pesquisa exploratória, descritiva e explicativa; pesquisa quanto aos procedimentos, abordando o estudo de caso, levantamento de dados, pesquisa bibliográfica, documental, participante e 
experimental; e a pesquisa quanto à abordagem do problema, compreendendo a pesquisa qualitativa e quantitativa.

\section{PROCEDIMENTOS METODOLÓGICOS}

O Congresso Brasileiro de Custos acontece desde 1994 e é dividido em 16 áreas: Gestão estratégica de custos, Desenvolvimento teóricos em custos, Aplicação de modelos quantitativos em custos, Custos da qualidade, Gestão de custos ambientais e responsabilidade social, Gestão de custos e Tecnologia da informação, Gestão de custos logísticos e nas cadeias produtivas, Gestão de custos nas empresas agropecuárias e agronegócios, Gestão de custos nas empresas de comércio e de serviços, Gestão de custos nas empresas de terceiro setor, Gestão de custos no setor governamental, Gestão de custos para micro, pequenas e médias empresas, Gestão do conhecimento e do Capital intelectual, Ensino e pesquisa na gestão de custos, Controladoria e Novas tendências aplicadas à gestão de custos.

A proposta metodológica desse trabalho é fazer uma análise bibliométrica da área "ensino e pesquisa na gestão de custos", do Congresso Brasileiro de Custos, no período que abrange 2007 a 2009. Para tanto, 49 trabalhos da área estudada foram selecionados: 15 artigos no ano de 2007, 16 trabalhos em 2008 e 18 artigos em 2009.

A área "ensino e pesquisa em gestão de custos" foi escolhida, por trazer estudos no que diz respeito à educação e pesquisa em Contabilidade, cada vez mais estudada nos últimos anos. Esse artigo tem como intuito mapear esses recentes estudos fazendo um levantamento dos dados com base nos anais do CBC, abrangendo a quantidade de autores por artigo, instituições nas quais os pesquisadores estão vinculados, temáticas levantadas, tipos de metodologia utilizados: abordagens, procedimentos e objetivos.

Esse trabalho é do tipo descritivo e, segundo Gil (1996), tem como objetivo descrever as características de uma determinada população. No caso desse estudo foi feita uma análise bibliométrica para se fazer um levantamento de forma quantitativa, no que tange ao mapeamento realizado e qualitativo ao avaliar as informações que foram analisadas nos 49 artigos do triênio 2007 a 2009.

\section{ANÁLISE E DISCUSSÃO DOS RESULTADOS}

Os resultados encontrados levam em consideração um levantamento feito com base nos 49 artigos na área "ensino e pesquisa em gestão de custo", no que diz respeito à quantidade de autores por artigo, instituições de ensino vinculadas, metodologias utilizadas e temáticas apresentadas. 


\subsection{Quantidade de autores e IES vinculadas}

O Congresso Brasileiro de Custos, no ano de 2007, permitia no máximo 4 autores por artigo e 3 artigos submetidos por autor para serem avaliados. A partir de 2008, o número de autores aumentou para o limite de 5 autores para cada trabalho apresentado. A tabela 1 mostra a quantidade de autores por artigo no triênio 2007 a 2009.

Tabela 1: Quantidade de autores por artigo no triênio 2007 a 2009

\begin{tabular}{c|c|c|c}
\hline Quantidade de autores & $\mathbf{2 0 0 7}$ & $\mathbf{2 0 0 8}$ & $\mathbf{2 0 0 9}$ \\
\hline 1 & 1 & - & 1 \\
\hline 2 & 5 & 4 & 4 \\
\hline 3 & 5 & 6 & 6 \\
\hline 4 & 4 & 2 & 4 \\
\hline 5 & - & 4 & 3 \\
\hline Total & $\mathbf{1 5}$ & $\mathbf{1 6}$ & $\mathbf{1 8}$ \\
\hline
\end{tabular}

Fonte: Elaborado pelos autores (2012)

A quantidade de artigos aprovados aumentou de 15 artigos em 2007 para 18 trabalhos no ano de 2009. Essa demanda aponta uma tendência dos congressos brasileiros da área de Contabilidade em se fazer trabalhos em ensino e pesquisa, ultimamente.

O gráfico 1 apresenta as IES citadas por regiões brasileiras, que foram vinculadas pelos autores nos trabalhos aprovados para o Congresso Brasileiro de Custos, na área "ensino e pesquisa em gestão de custo".

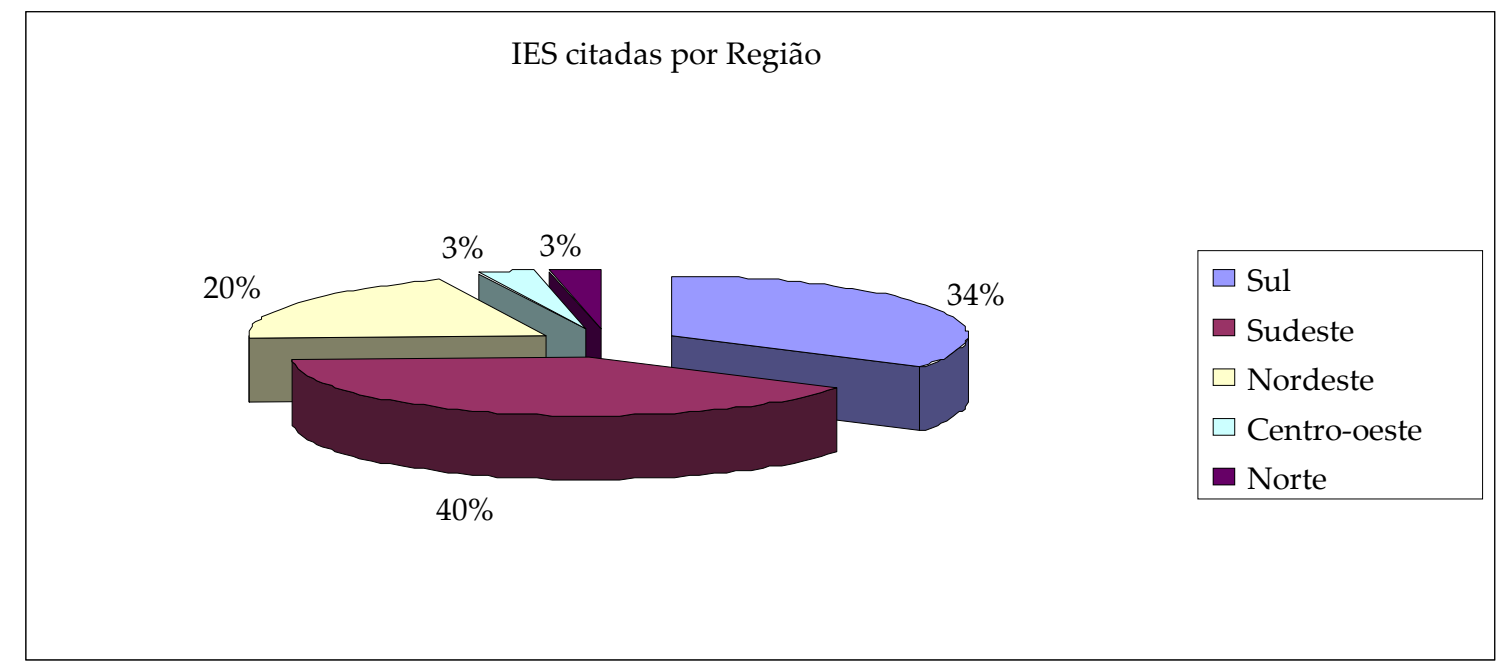

Gráfico 1: Instituições de Ensino vinculadas pelos autores por região

Fonte: Elaborado pelos autores (2012). 
$\mathrm{Na}$ distribuição das IES pelas regiões brasileiras, tem-se 12 instituições na região Sul, correspondendo 34\% do total de trabalhos vinculados; 15 instituições (40\%) na região Sudeste; 7 IES (20\%) da região Nordeste e 3\% nas regiões Norte e Centro-oeste, respectivamente, com um 1 trabalho cada.

\begin{tabular}{|l|c|}
\hline \multicolumn{1}{|c|}{ Instituição } & Sigla \\
\hline Universidade do Rio Sinos & UNISINOS \\
\hline Universidade Federal de Uberlândia & UFA \\
\hline Universidade de São Paulo & USP \\
\hline Universidade Estadual de Londrina & UFPR \\
\hline Universidade Federal do Paraná & FACINTER \\
\hline Faculdade Internacional de Curitiba & UCB \\
\hline Universidade Católica de Brasília & UNL \\
\hline Universidade Nova de Lisboa & FURB \\
\hline Universidade Regional de Blumenau & UNOPAR \\
\hline Universidade Norte do Paraná & UFCG \\
\hline Universidade Federal de Campina Grande & USP-RP \\
\hline Universidade de São Paulo - Ribeirão Preto & EESC \\
\hline Escola de Engenharia de São Carlos & UNIFEBE \\
\hline Centro Universitário de Brusque & MARKENZIE \\
\hline Universidade Presbiteriana & UFSM \\
\hline Universidade Federal de Santa Maria & UFRGS \\
\hline Universidade Federal do Rio Grande do Sul & COC \\
\hline Faculdade Interativa & UFSC \\
\hline Universidade Federal de Santa Catarina & UFBA \\
\hline Universidade Federal da Bahia & FTC \\
\hline Faculdade de Tecnologia e Ciência & UENP \\
\hline Universidade Estadual do Norte do Paraná & UEM \\
\hline Universidade Estadual de Maringá & UEPG \\
\hline Universidade Estadual de Ponta Grossa & IPA \\
\hline Instituto Agronômico de Pernambuco & UFPB \\
\hline Universidade Federal da Paraíba & UFRJ \\
\hline Universidade Federal do Rio de Janeiro & UERJ \\
\hline Universidade Estadual do Rio de Janeiro & UNESC \\
\hline Centro Universitário do Espírito Santo & UNIFIL \\
\hline Centro Universitário Filadélfia & UNASP \\
\hline Centro Universitário Adventista de São Paulo & PUC \\
\hline Pontifícia Universidade Católica de São Paulo & UFPE \\
\hline Universidade Federal de Pernambuco & FAFICA \\
\hline Faculdade Maurício de Nassau & UFRR \\
\hline Faculdade de Filosofia de Caruaru & \\
\hline Universidade Federal de Roraima & \\
\hline Una 3: & \\
\hline
\end{tabular}

Quadro 3: Instituições vinculadas pelos autores

Fonte: Anais do Congresso Brasileiro de Custos (Triênio 2007-2009) 
No que diz respeito ao número de IES envolvidas, através da vinculação feita por parte dos autores, chegou-se ao número de 36 instituições, conforme apresentou o quadro 3. A tabela 2 apresenta, das instituições acima citadas, as que mais tiveram artigos aprovados no triênio da área pesquisada foram: FURB, com 8 trabalhos; UFSC e a UFRJ, com 4 artigos, cada; UFU com 3 trabalhos; USP e a UFPB, com 2 artigos cada.

Tabela 2: Produção das IES que mais produziram no triênio 2007 a 2009

\begin{tabular}{c|c|c|c|c}
\hline IES & 2007 & 2008 & 2009 & Total \\
\hline FURB & 3 & 2 & 3 & 8 \\
\hline UFSC & - & 2 & 2 & 4 \\
\hline UFRJ & - & - & 4 & 4 \\
\hline UFU & 2 & 1 & - & 3 \\
\hline USP & 1 & 1 & - & 2 \\
\hline UFPB & - & 1 & 1 & 2 \\
\hline
\end{tabular}

Fonte: Elaborado pelos autores (2012)

É importante salientar que a Universidade Regional de Blumenau produziu nos 3 anos, consecutivamente e a Universidade Federal do Rio de Janeiro teve sua produção concentrada somente no ano de 2009. Isso comprova o que dizem Ahrens e Chapman (2006), que é relevante saber qual universidade os autores estão vinculados.

\subsection{Metodologias utilizadas nos artigos}

No triênio levantado de 2007 a 2009, foram aprovados 49 artigos, que passaram por uma análise em relação as metodologias utilizadas, em relação à abordagem qualitativa ou quantitativa; aos procedimentos da pesquisa: levantamento de dados, documental, bibliográfica, estudo de caso, multi-casos, pesquisa-ação e experimental e quanto aos objetivos: exploratória ou descritiva. A tabela 3 mostra um resumo das metodologias.

Tabela 3: Metodologias utilizadas nos 49 artigos apresentados no triênio

\begin{tabular}{l|c|c|c}
\hline Abordagem & $\mathbf{2 0 0 7}$ & $\mathbf{2 0 0 8}$ & $\mathbf{2 0 0 9}$ \\
\hline Qualitativa & 5 & 6 & 13 \\
\hline Quantitativa & 10 & 10 & 5 \\
\hline Total & 15 & 16 & 18 \\
\hline Procedimentos & $\mathbf{2 0 0 7}$ & $\mathbf{2 0 0 8}$ & $\mathbf{2 0 0 9}$ \\
\hline Levantamento & 8 & 10 & 7 \\
\hline Documental & 2 & 5 & 9 \\
\hline Bibliográfica & 2 & 1 & 1 \\
\hline Estudo de caso & - & - & 1 \\
\hline
\end{tabular}




\begin{tabular}{l|c|c|c}
\hline Multi-casos & 1 & - & - \\
\hline Pesquisa-ação & 1 & - & - \\
\hline Experimental & 1 & - & - \\
\hline Total & 15 & 16 & 18 \\
\hline Objetivos & $\mathbf{2 0 0 7}$ & $\mathbf{2 0 0 8}$ & $\mathbf{2 0 0 9}$ \\
\hline Exploratória & 4 & 7 & 7 \\
\hline Descritiva & 11 & 9 & 11 \\
\hline \multicolumn{1}{c|}{ Total } & $\mathbf{1 5}$ & $\mathbf{1 6}$ & $\mathbf{1 8}$ \\
\hline
\end{tabular}

Fonte: Elaborado pelos autores (2012)

Em relação à abordagem dada, as pesquisas da área "ensino e pesquisa em gestão de custos" estão divididas em qualitativas: 33,33\% em 2007; 37,50\% em 2008 e $72,22 \%$ em 2009. As pesquisas do tipo quantitativas apresentam-se da seguinte forma: 66,67\% em 2007; 62,50\% em 2008 e 27,78\% em 2009. Observa-se uma preferência pelos autores por pesquisas quantitativas em 2007 e 2008, porém nota-se o crescimento significativo da pesquisa qualitativa em 2009. O gráfico 2 evidencia que, no triênio, $51 \%$ dos trabalhos foram quantitativos e $49 \%$ das pesquisas foram qualitativas.

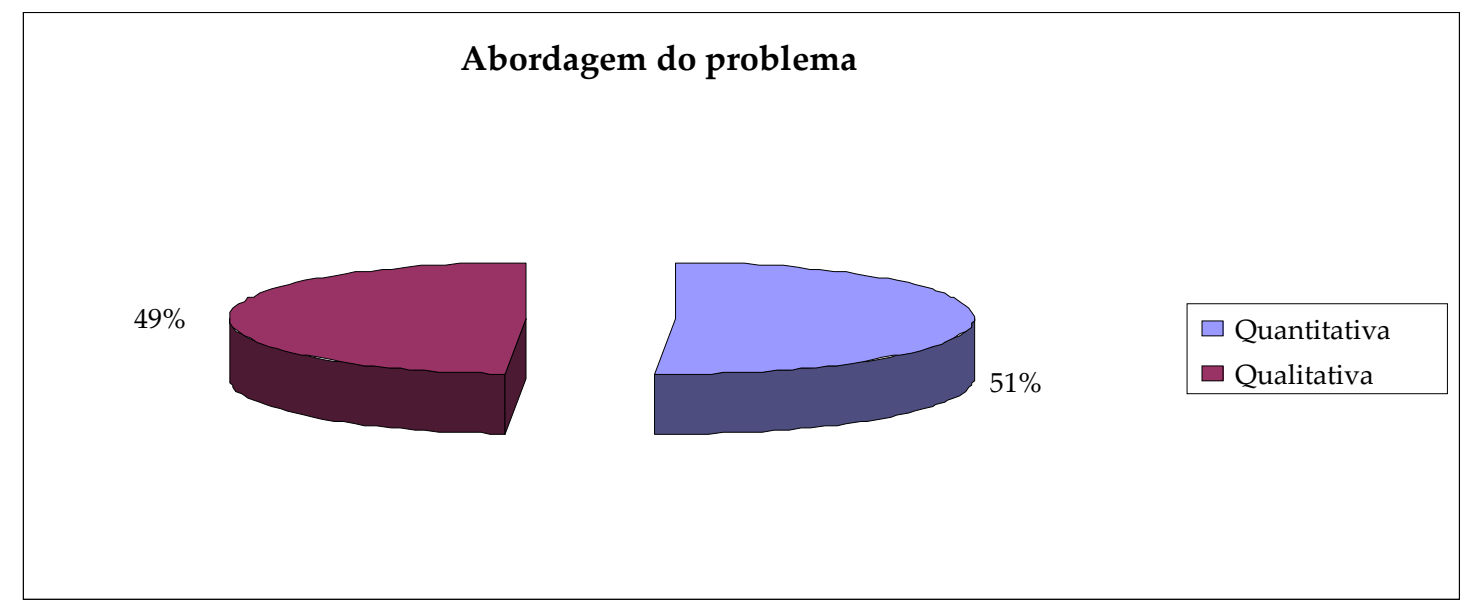

Gráfico 2: Tipo de pesquisas quanto à abordagem do problema

Fonte: Elaborado pelos autores (2012)

Já em relação aos procedimentos adotados nos artigos selecionados, obteve-se o seguinte resultado: em 2007, 53,33\% foram feitos levantamento de dados; $13,33 \%$ são pesquisas documentais; $13,33 \%$ bibliográficas e 6,67\% de multi-casos, pesquisaação e experimental, respectivamente. Em 2008, 62,50\% são de levantamento de dados; $31,25 \%$ trabalhos documentais e $6,25 \%$ de pesquisas bibliográficas. Já no ano de 2009, 38,88 foram de levantamento; 50\% de pesquisas documentais e 5,56\% bibliográficas e estudo de caso, cada.

De acordo com Gil (2010) a pesquisa documental se aproxima da pesquisa bibliográfica uma vez que ambas utilizam dados já existentes. Contudo, a principal diferença está na natureza das fontes, pois a primeira vale-se de consulta de material 
interno à organização, enquanto a segunda obtém dados em biblioteca ou em banco de dados. Silva (2010), seguindo a mesma linha de raciocínio de Gil (2010), complementa afirmando que a pesquisa documental usa material que ainda não teve tratamento analítico e a pesquisa bibliográfica discute um tema baseado em referências já publicadas em livros e revistas.

Ainda em relação à tabela 3, pode-se dizer que houve um crescimento pelo tipo de pesquisa documental, que passou de $13,33 \%$ em 2007 para $50 \%$ em 2009. Por sua vez, o procedimento do tipo levantamento de dados sofreu uma queda de 2007 a 2009.

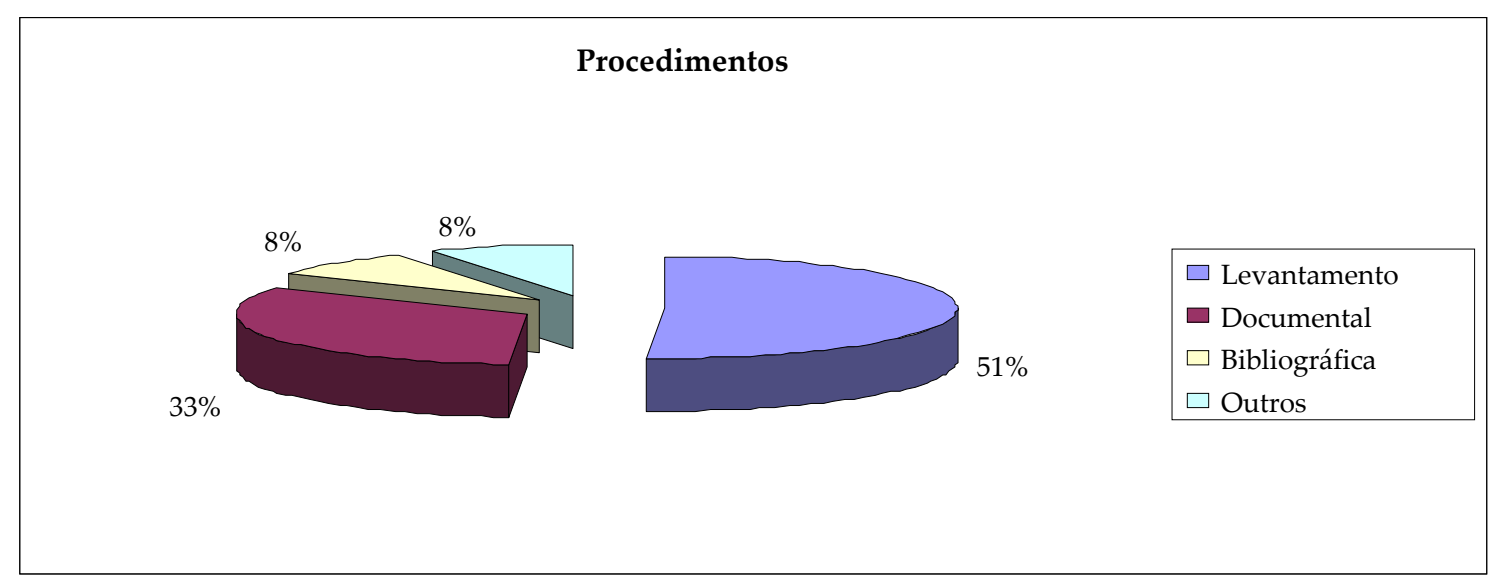

Gráfico 3: Tipos de pesquisa quanto aos procedimentos

Fonte: Elaborado pelos autores (2012)

O gráfico 3 mostra, quanto aos procedimentos de pesquisa adotados pelos autores, que os tipos mais utilizados foram os trabalhos feitos com base em levantamento de dados (51\%), documental (33\%), bibliográfica ( $8 \%$ ) e outros (estudo de casos, multi-casos, pesquisa-ação e experimental) com $8 \%$.

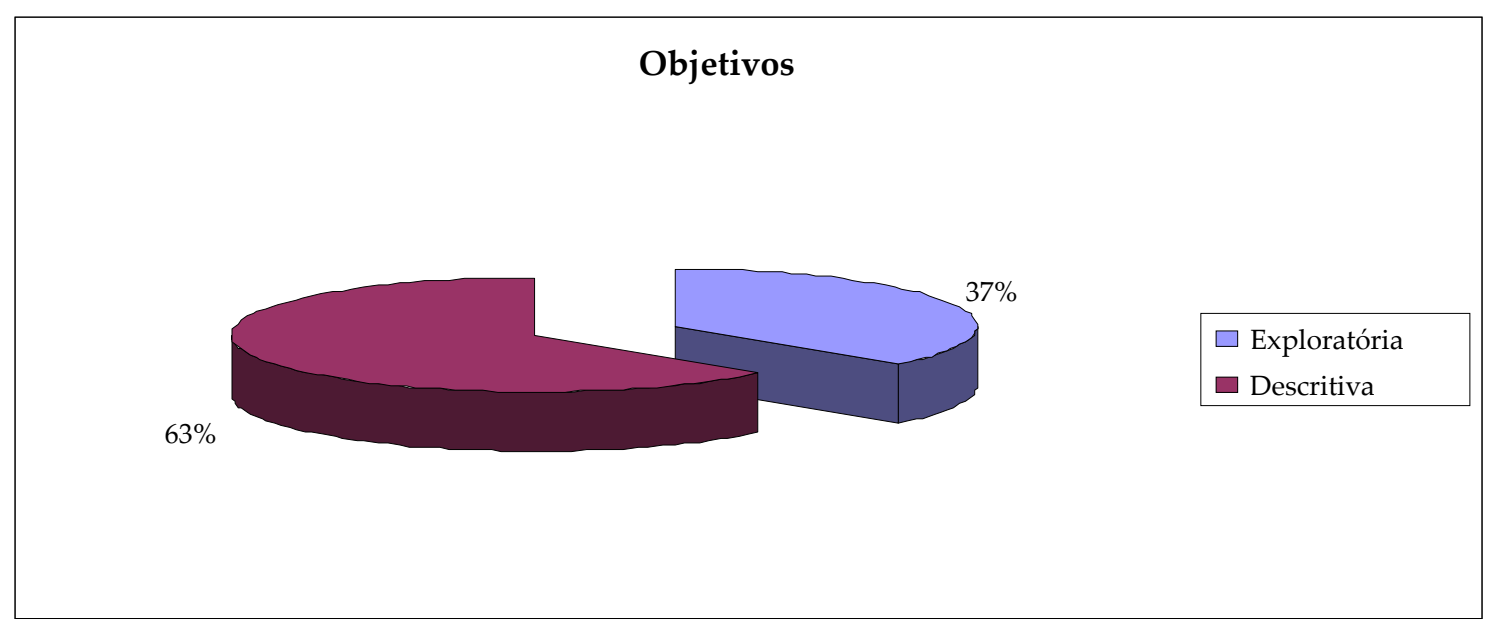

Gráfico 4: Tipos de pesquisa quanto aos objetivos

Fonte: Elaborado pelos autores (2012) 
Já o gráfico 4 apresenta, quantos aos objetivos, os tipos de pesquisas elaboradas no triênio: 63\% exploratórias e 37\% descritivas. Em 2007, 26,66\% dos trabalhos foram exploratórios e 73,34\% descritivos; já no ano de 2008, houve um aumento das pesquisas exploratórias, num percentual de $43,75 \%$ e as descritivas foram de 56,25\%; em relação a 2009, obteve-se $38,88 \%$ dos trabalhos como exploratórios e $61,12 \%$ como descritivos.

Em relação aos tipos de pesquisa quanto aos aspectos metodológicos: abordagens, procedimentos e objetivos, pode-se dizer que está condizente com o estudo Hesford, Van Der Stede e Young (2007) quando afirmam que em um estudo bibliométrico, a metodologia abordada pelos autores deve ser levantada.

\subsection{Temáticas dos artigos}

As temáticas dos artigos aprovados na área "ensino e pesquisa em gestão de custos" são das mais variadas possíveis. A tabela 4 relaciona os temas abordados, com base nos títulos criados pelos autores no triênio 2007-2009.

Tabela 4: Temáticas dos artigos aprovados na área estudada

\begin{tabular}{|c|c|c|c|}
\hline Temáticas & 2007 & 2008 & 2009 \\
\hline Publicações sobre ABC & 1 & - & - \\
\hline Conhecimento na academia contábil & 1 & - & - \\
\hline Didática na Contabilidade & 1 & - & - \\
\hline Aprendizagem nas disciplinas de custos e gerencial & 2 & - & - \\
\hline Risco empresarial: participação tributária dos estados & 1 & - & - \\
\hline Técnicas de ensino Contabilidade de custos & 4 & - & - \\
\hline Jogos de empresa na disciplina controladoria & 1 & - & - \\
\hline Terminologia na área de custos & 1 & - & - \\
\hline Ensino Custeio ABC & 1 & - & - \\
\hline Desempenho nas atividades acadêmicas em Contabilidade & 1 & - & - \\
\hline Matriz de Slack: estudo multi-casos & 1 & - & - \\
\hline Estudo bibliométrico: controladoria/logística/cadeia & - & 1 & - \\
\hline Teoria da revolução científica: artigos em contabilidade & - & 1 & - \\
\hline Qualidade discente em custo aplicado à administração & - & 1 & - \\
\hline Competências dos professores de Controladoria & - & 1 & - \\
\hline Área Ensino e Pesquisa em Contabilidade - Congresso USP & - & 1 & - \\
\hline Estudo presencial x EAD & - & 2 & 1 \\
\hline Efeito Sunk Cost: efeito teórico dos discentes & - & 1 & - \\
\hline Saberes na Contabilidade & - & 1 & - \\
\hline Teoria das filas ao time driven ABC model & - & 1 & - \\
\hline Instituições e pesquisadores na Revista RCF & - & 1 & - \\
\hline Curso de Ciências Contábeis nas IES - ótica dos egressos & - & 1 & - \\
\hline Artigos sobre custos hospitalares - Congresso USP & - & 1 & - \\
\hline Cursos de Pós na área de terceiro setor & - & 1 & - \\
\hline Ensino à distância em um curso de PPGCC & - & 1 & - \\
\hline
\end{tabular}




\begin{tabular}{|c|c|c|c|}
\hline Abordagem Positiva e Normativa - pesquisas em contabilidade & - & 1 & - \\
\hline Percepção dos docentes com base na Teoria das restrições & - & - & 1 \\
\hline Produção bibliográfica nos PPGCC: custos x gerencial & - & - & 1 \\
\hline Fatores de atração dos alunos ao curso de Ciências Contábeis & - & - & 1 \\
\hline Tendências, desafios e perspectivas nos PPGCC & - & - & 1 \\
\hline Ação docente nos cursos de Ciências Contábeis & - & - & 1 \\
\hline Método de estudo de caso - formação profissional do contador & - & - & 1 \\
\hline Desempenho ENADE - custos & - & - & 2 \\
\hline Diretrizes curriculares - custos & - & - & 1 \\
\hline Pesquisa sobre estudo de casos em contabilidade e administração & - & - & 1 \\
\hline Pesquisa sobre satisfação no Congresso Brasileiro de Custos & - & - & 1 \\
\hline Estudo bibliométrico sobre TOC & - & - & 1 \\
\hline Competências dos contadores x perfil desejado pelas empresas & - & - & 1 \\
\hline Contabilidade ambiental nos cursos de Ciências Contábeis & - & - & 1 \\
\hline Taxionomia de objetivos educacionais - custos & - & - & 1 \\
\hline Pesquisa sobre oferta de conhecimento aos futuros contadores & - & - & 1 \\
\hline Valores sociais e práticas de gestão patrimonial & - & - & 1 \\
\hline Total & 15 & 16 & 18 \\
\hline
\end{tabular}

Fonte: Elaborado pelos autores (2012).

As 43 temáticas apresentadas no CBC demonstram a variedade de assuntos levantados pelos autores no triênio 2007-2009. Observa-se que, dificilmente os temas se repetem, com exceção de "estudo presencial x EAD" com 2 artigos em 2008 e 1 em 2009, perfazendo um total de 3 trabalhos. Esse achado está de acordo com a teoria de Pritchard (1969), que acredita na dispersão dos assuntos científicos, ou seja, em um número maior de temáticas dentro de uma área.

Em 2007, o tema "aprendizagem nas disciplinas de custos e gerencial" teve dois artigos aprovados e "técnicas de ensino em contabilidade de custos" obteve quatro trabalhos selecionados. A temática "ensino presencial x EAD", no ano de 2008, foi contemplada com 2 artigos. Já em 2009, a temática “desempenho ENADE custos" teve 2 trabalhos aprovados.

O gráfico 5 mostra 49 artigos aprovados divididos da seguinte forma: ensino com 22 trabalhos, perfazendo um percentual de $45 \%$ e pesquisa com 27 artigos selecionados, com $55 \%$ do total. 


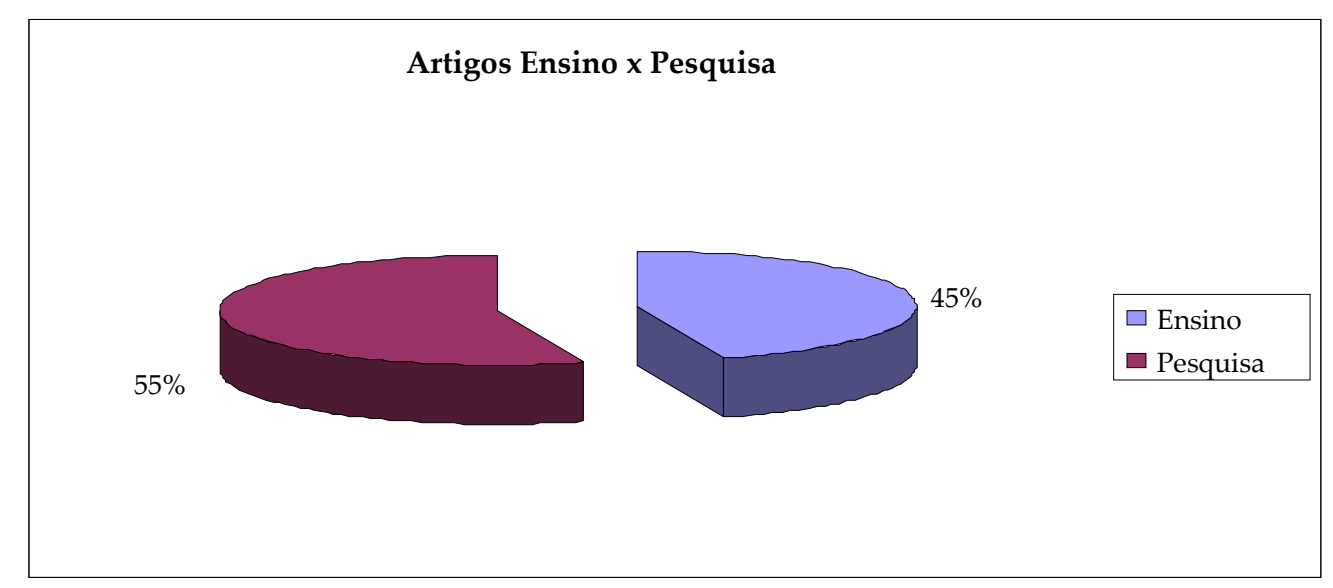

Gráfico 5: Artigos divididos em Ensino x Pesquisa

Fonte: Elaborado pelos autores (2012).

Dos artigos selecionados, confirmando os resultados encontrados na pesquisa de Willians e Rodgers (1996) relacionada à estratificação, somente 17 estão ligados à área de custos, correspondendo a 34,69\%, 27 trabalhos $(55,11 \%)$ estão ligados à Contabilidade, de uma forma geral e 5 artigos (10,20\%) estão relacionados à áreas afins, com as seguintes temáticas: efeito sunk cost, risco empresarial, gestão patrimonial, matriz de Slak e terceiro setor.

\section{CONSIDERAÇÕES FINAIS}

O trabalho teve como tema um estudo bibliométrico no triênio 2007-2009 da área ensino e pesquisa em gestão de custos do Congresso Brasileiro de Custos. Para tanto, partiu-se de um objetivo geral para responder a pergunta da pesquisa, ou seja, quais são os tipos de metodologia e temáticas utilizados pelos autores envolvidos nos trabalhos selecionados nessa área que faz parte do $\mathrm{CBC}$, no triênio estudado.

Os resultados que foram encontrados tem como base um levantamento feito com base nos 49 artigos na área "ensino e pesquisa em gestão de custo", no que diz respeito à quantidade de autores por artigo, instituições de ensino vinculadas, metodologias utilizadas e temáticas apresentadas.

Em relação à quantidade de autores por artigo, os artigos são compostos por 3 pesquisadores, em média. A região com $40 \%$ de trabalhos aprovados é a Sudeste, sendo que no triênio analisado, a FURB (Universidade Regional de Blumenau) teve 8 artigos selecionados, entre as 36 Instituições de Ensino Superior que aprovaram textos na área temática estudada.

As metodologias utilizadas pelos autores levam em consideração as abordagens, procedimentos e os objetivos da pesquisa. Quanto às abordagens, 51\% dos trabalhos são quantitativos, havendo uma tendência pela busca em trabalhos qualitativos nos últimos anos. Já em relação aos procedimentos, 51\% dos trabalhos 
foram de levantamento de dados e 33\% são documentais. Quanto aos objetivos, 63\% das pesquisas são descritivas.

Das temáticas utilizadas, as principais foram: técnicas de ensino em contabilidade de custos, estudo presencial versus ensino à distância e desempenho no ENADE na área de custos. A área de ensino teve a aprovação de $45 \%$ dos trabalhos, já 55\% foram de artigos relacionados à pesquisa. Um fato interessante é que dos 49 trabalhos aprovados somente 17 estão relacionados a custos, os demais tem ligação direta com Contabilidade e áreas afins, comprovando o que diz a teoria sobre estratificação, ou seja, uma separação da área estudada.

\section{REFERÊNCIAS}

ABC - ASSOCIAÇÃO BRASILEIRA DE CUSTOS. Disponível em: http://www.abcustos.org.br/. Acesso em: 13 abr. 2010.

AHRENS, C; CHAPMAN, C.S. Doing Qualitative Field Research in Management Accounting: Positioning data to Contribute to Theory. Accounting, Organizations and Society, n,. 31, p. 818-819, 2006.

ARAÚJO, E. A. T.; OLIVEIRA, V.do C.; SILVA, W. A. C. Estudo bibliométrico da produção cientifica sobre Contabilidade Gerencial. In: CONGRESSO USP DE CONTABILIDADE, 9, 2010, São Paulo. Anais... São Paulo, USP, v. 9, p. 1-17, 2009.

BRASIL. CES/u/CFE. Parecer 977, de 03 de dezembro de 1965. Diário Oficial da União: 20 de janeiro de 1966. Brasília/DF, 1965.

CARDOSO, R. L.; MENDONÇA NETO, O. R.; RICCIO, E. L.; SAKATA, M. C. G. Pesquisa Científica em Contabilidade entre 1990 e 2003. Revista de Administração de Empresas. v. 43. Jun, 2005.

FARO, M. C. S. C.; SILVA, R. N. S. A Natureza da Pesquisa em Contabilidade Gerencial - Análise Bibliométrica de 1997 à 2007 nos Principais Periódicos Internacionais. In: Anais... EnANPAD, 32. 2008, Rio de Janeiro. Anais... Rio de Janeiro: ANPAD, 2008.

GIL, A. C. Como elaborar uma monografia. 3ª ed. São Paulo: Atlas, 1996.

2010.

. Como elaborar projetos de pesquisas. 5a ed. São Paulo: Atlas, 
HESFORD, J. W.; LEE, S.; VAN DER STEDE, W. A.; YOUNG, S. M. Management Accounting: A Bibliographic Study. In C. S. Chapman, A. G. Hopwood \& M. D. Shields (Org.). Handbook of Management Accounting Research. Elsevier, 2007.

JOHNSON, H. Thomas; KAPLAN, Robert S. Contabilidade gerencial: a restauração da relevância da contabilidade nas empresas. Rio de Janeiro: Campus, 1993.

KROENKE, A.; CUNHA, J. V. A. Harmonização Contábil: Um Estudo Bibliométrico no Congresso Usp e EnANPAD de 2004 à 2007. Disponível em: $<$ http://www.ead.fea.usp.br/semead/11semead/resultado/an_resumo.asp?cod_trabalh o=743>. Acesso em: 10 abr 2010.

LEITE FILHO, G. A. Padrões de Produtividade de Autores em Periódicos e Congressos na Área de Contabilidade no Brasil: Um Estudo Bibliométrico. Disponível em: <http://www.congressousp.fipecafi.org/artigos62006/84.pdf>. Acesso em: 16 abr. 2010.

MENDONÇA NETO, O. R.; CARDOSO, R. L.; RICCIO, E. L.; SAKATA, M. C. G. Estudo sobre as Publicações Científicas em Contabilidade: uma Análise de 1990 até 2003. In:ENANPAD, 28. 2004, Curitiba. Anais... Rio de Janeiro: ANPAD, 2004.

OLIVEIRA, M. C. Análise dos Periódicos Brasileiros de Contabilidade. Revista Contabilidade \& Finanças - USP. São Paulo, n. 29, p. 68-86, maio/ago, 2002.

PRITCHARD, A. Statistical bibliorgrahy or bibliometricas? Jornaul of documentation, v. 25, n. 4, p. 348-349, 1969.

RAUPP, Fabiano Maury; BEUREN, Ilse Maria. Metodologia da pesquisa aplicável às Ciências Sociais. In: BEUREN, Ilse Maria (org). Como elaborar trabalhos monográficos em contabilidade: teoria e prática. 2ª ed. São Paulo: Atlas, 2004.

RYAN, Bob, SCAPENS, Robert W. e THEOBALD, Michael. Metodología de la investigación em finanzas e contabilidad. Barcelona: Ediciones Deusto, 2004.

SILVA, A. C. R. da. Metodologia da pesquisa aplicada à contabilidade: orientações de estudos, projetos, artigos, relatórios, monografias, dissertações e teses. $3^{\text {a }}$ ed. São Paulo: Atlas, 2010.

SILVA, F. C. C.; ALBUQUEQUE, K. S. L. S.; GOMES, S. M. S. Discussão sobre a Controvérsia do Paradigma Econômico na Pesquisa Empírica em Contabilidade 
Gerencial. In: Encontro da Associação Nacional de Pós-graduação e Pesquisa em Administração, 32. 2008, Rio de Janeiro. Anais... Rio de Janeiro: ANPAD, 2008.

SILVA, J. M. P. da S. O estado-da-arte da literatura em economia e gestão da inovação e tecnologia: um estudo bibliométrico. 2008. 77f. Dissertação (Mestrado em Inovação e Empreendedorismo Tecnológico). Faculdade de Engenharia, Universidade do Porto, Porto, 2008.

WILLIANS, P. F.; RODGERS, J. L. Patterns of research productivity and knowledge creation at the accounting review: 1967-1993. The Accounting Historians Journal, 23(1), 445-470, 1996. 